\title{
A PRÁtica da GESTÃo PARTICIPATIVA EM ESCOLAS MUNICIPAIS DE FORTALEZA
}

\section{1- Lydia Maria Pinto Brito, Universidade Potiguar - UNP lydiampbrito@yahoo.com.br}

\author{
2- Maria Eliane Alves Lobo \\ Universidade Estadual do Ceará - UECE \\ elianepesquisa@yahoo.com.br
}

\section{RESUMO}

Este artigo trata do relato de pesquisa sobre o tema da gestão participativa na organização escolar, com o objetivo de investigar como a prática da gestão participativa é percebida por seus usuários: estudantes, professores, funcionários, especialistas, pais e pelos próprios gestores. A pesquisa realizada em 12 (doze) escolas, entrevistando, observando e aplicando questionários específicos aos diferentes segmentos, no total de 682 (seiscentos e oitenta e dois) participantes, verificou que a gestão participativa ainda é um modelo em aprendizagem. A discussão parte de uma concepção do modelo de gestão escolar preconizado na lei federal $n^{\circ}$ 9.394, na Constituição Estadual do Ceará, na Lei Orgânica do Município de Fortaleza, no eixo da reforma administrativa da prefeitura de Fortaleza, nas capacitações dos gestores e nos princípios filosóficos da educação e da gestão escolar para o século XXI. As considerações finais diante ao pano de fundo das mudanças institucionais e gerenciais, apontam que a gestão participativa é um modelo em aprendizagem.

Palavras-Chave

Gestão. Educação. Gestão Participativa, Teoria Organizacional, Modelo de Gestão.

\section{ABSTRACT}

This article treats of the research report about the theme of participative management in school organization, with the objective of investigating how the practice of the shared administration is perceived by its users: students, teachers, public workers, specialists, parents and by managers themselves. The research carried out in 12 (twelve) schools, making interviews, observing and applying specific question forms, totaling 682 (six hundred and eighty two) participants, have verified that the participative management is still a model in the phase of learning. The discussion starts from a conception of the model of school management praised in Federal Law 9.394, in the Constitution of the State of Ceará, in the Organic Law of the Municipality of Fortaleza, in the axis of the administrative reformation of the prefectural Government of Fortaleza, in management staff capacitation and in the education and school management philosophical principles for the XXI century. The results, before the background of institutional and administration changes, lead to conclude that the subjects perceive under the influence of their educational base, values and culture.

Keywords

Management.Education. Shared Management, Organizational Theory, Management Model. 


\section{Introdução}

A Comissão Internacional sobre a Educação para o Século XXI, instaurada pela UNESCO, em $1993 \mathrm{com}$ a finalidade de identificar as tendências da educação nas próximas décadas, divulgou em 1996 seu relatório conclusivo, conhecido como o Relatório Jacques Delors. Dentre as muitas questões tratadas, o relatório, elaborado por especialistas de vários países, indica os quatro pilares para a educação do século XXI: 1 . aprender a aprender; 2. aprender a fazer; 3. aprender a viver junto; 4. aprender a ser. Concebidos como vias de acesso ao conhecimento e ao convívio social democrático, eles redimensionam o papel do professor, o cotidiano vivido nas instituições educacionais e apontam caminhos para a gestão escolar.

No Brasil, a Lei de Diretrizes e Bases da Educação Nacional - Lei Federal no 9.394/96 evidencia este novo paradigma ao definir no seu art. $12^{\circ}$, a incumbência dos estabelecimentos de ensino, respeitadas as normas comuns e as do seu sistema de ensino, principalmente no inciso VI que reza: "articular-se com a família e a comunidade criando processos de integração da sociedade com a escola" (apud CARNEIRO, 2008, p. 73).

Os princípios filosóficos da educação nacional, acentuados nos incisos do art. 14 da referida lei, dizem: "I - participação dos profissionais da educação na elaboração do projeto pedagógico da escola; II - participação da comunidade escolar e local em conselhos escolares ou equivalentes" (LDB). Encontra-se nos princípios, a nova lógica que aponta a necessidade precípua do modelo de gestão participativa. Nesta perspectiva, a educação já concebida como direito de todos, concebe também, a gestão escolar como compromisso de todos. Saindo da centralidade do diretor escolar enquanto figura do poder exclusivo das decisões, a nova concepção de gestão cria a pluralidade de caminhos para atender às expectativas da sociedade que incidem sobre a escola no mundo contemporâneo.

No modelo de gestão participativa, o projeto político-pedagógico e o conselho escolar são instrumentos formais, mediadores e representativos da autonomia e das relações democráticas. A partir dos pressupostos destes instrumentos, coletivamente construídos, a organização escolar redimensiona sua missão e sua função social na perspectiva de formação do cidadão crítico. Mecanismos e estratégias são criados com suporte em princípios democráticos da modernidade, constituindo um universo ramificado e complexo a fazer frente à abordagem linear que costumava estruturar o trabalho da administração escolar numa perspectiva tradicional.
$\mathrm{Na}$ gestão participativa, as práticas escolares reforçam e exercitam as propostas de organização democrática da escola e da sociedade como um todo, através de mecanismos e estratégias como os fóruns, a resolução de conflitos, os grêmios escolares, os regulamentos coletivamente construídos, etc. Contudo, estas experiências de participação não poderiam ficar confinadas às quatro paredes da escola. Mas, alcançar as famílias e as outras pessoas da comunidade, o que redimensiona a ação do gestor escolar nesta nova abordagem, com demandas de estratégias de integração com os pais e a comunidade.

A Constituição Estadual do Ceará, no artigo 215, inciso $\mathrm{V}$, anuncia: "gestão democrática da instituição escolar na forma de lei, garantidos os princípios de participação de representantes da comunidade"; garantindo, assim, o princípio da participação. A Lei Orgânica do Município de Fortaleza, artigo 221, alínea "e", o artigo 226, inciso $\mathrm{V}$ e $\mathrm{o}$ artigo 230 prevêem a administração participativa na escola pública da rede municipal de ensino.

Neste contexto oficial, em que a Secretaria Municipal de Educação, antiga SEDAS, órgão responsável pela educação pública no município de Fortaleza (CE), já tenha promovido capacitações para diretores, sistematizado os conselhos escolares, capacitado seus membros, construído coletivamente o Projeto Político-Pedagógico das escolas, pressupõe-se identificar na rede de escolas, um perfil de gestão democrática e de ensino/aprendizagem orientados pelo princípio da participação, onde se questiona: como a prática da gestão participativa é percebida pelos usuários das escolas?

Para conhecer, na prática, as estratégias da gestão escolar local, considerando o cenário oficial e formalizado no processo de eleição de diretores, configura-se relevante questão em meio às discussões emergentes de uma sociedade democrática. Conhecer as práticas gestoras que a escola usa na construção do sujeito participativo, não pode fugir ao interesse acadêmico, político e social, na vigência do século XXI, já profundamente identificado pela economia globalizada, pelo desenvolvimento tecnológico, mas também pela violência.

A análise da gestão participativa se justifica, a partir da compreensão que a escola é o locus onde a dinâmica do conjunto de ações integradas entre Sistema - Escola - Comunidade se efetiva, refletindo um modelo de gestão, permitindo então, o confronto entre as teorias propostas e as práticas gestoras consolidadas na rede pública municipal de ensino. O esforço empreendido na pesquisa da gestão participativa da escola pública justifica-se, 
outrossim, no contexto contemporâneo, diante do grande número de debates a respeito da teoria da educação, em vários países do mundo, os quais defendem a temática da autonomia, da descentralização e da participação como pressupostos básicos da gestão democrática.

Nesta problematização, o objetivo geral da pesquisa de campo consistiu em analisar a percepção dos usuários das escolas públicas municipais da Secretaria Executiva Regional II SER II, sobre as práticas da gestão participativa. Objetivos secundários foram também propostos como facilitadores da tarefa principal da pesquisa: 1. conhecer as principais realizações da gestão escolar na prática, na perspectiva da gestão participativa; 2. verificar os procedimentos efetivos na dinâmica da relação escola-comunidade; 3 . identificar os graus de participação dos diversos segmentos componentes da comunidade escolar. O objetivo deste artigo consiste em expor os resultados dos estudos e da investigação científica realizados, com o pressuposto que a gestão participativa ainda é um modelo em aprendizagem.

\section{O Contexto, O Método e O Material}

A rede municipal de ensino do Município de Fortaleza está organizada administrativamente em 6 (seis) Secretarias Executivas Regionais que administram os serviços educacionais à população através do Distrito de Educação. A pesquisa foi realizada no conjunto delimitado de 12 (doze), escolas da jurisdição da SER II.

Quadro 1 - Relação das Escolas Patrimoniais da SER II

\begin{tabular}{|ll|}
\hline \multicolumn{1}{|c|}{ ESCOLA MUNICIPAL DE ENSINO INFANTIL E FUNDAMETAL } \\
\hline 1. & José Ramos Torres de Melo \\
\hline 2. & Maestro Eleazar de Carvalho \\
\hline 3. & Professor Álvaro Costa \\
\hline 4. & Godofredo de Casto Filho \\
\hline 5. & João de Moura \\
\hline 6. & Professora Aída Santos e Silva \\
\hline 7. & Frei Agostinho Fernandes \\
\hline 8. & Professora Belarmina Campo \\
\hline 9. & José Carlos de Pinho \\
\hline 10. & Professor Luís Costa \\
\hline 11. & Almerinda de Albuquerque \\
\hline 12. & Professora Antonieta Cals \\
\hline
\end{tabular}

Fonte: Secretaria Executiva Regional II 2005

Nas escolas do quadro 1, foram pesquisados os segmentos diretamente envolvidos no trabalho com o gestor: vice-diretor, especialista, professor e funcionário, bem como os próprios gestores, estudantes e pais, totalizando o universo de 682 (seiscentos e oitenta e duas) pessoas pesquisadas, com a seguinte composição: 11 (onze) diretores, 6 (seis) vice-diretores, 8 (oito) especialistas, 208 (duzentos e oito) professores, 17 (dezessete) funcionários, 400 (quatrocentos) estudantes e 32 (trinta e dois) pais.

Na construção do perfil dos pais de alunos participantes da pesquisa, destaca-se que 68\% têm filhos matriculados na $6^{\text {a }}$ série, $40,6 \%$ estão vinculados à escola entre 6 a 9 anos e 46,6\% têm instrução de nível médio sendo o maior grau de instrução identificado no grupo, seguido por 40,6\% com ensino fundamental completo e o percentual de $6,3 \%$ disse não ter escolaridade. Faz-se necessário esclarecer que os referidos pais de alunos não são necessariamente os pais de estudantes participantes. Dentre o segmento de servidores participaram 239 , sendo $87 \%$ de professores, 7,1\% de funcionários (secretário escolar e agente administrativo), 3,3\% de especialistas (supervisor e orientador) e 2,5\% de vice-diretor.

Já o segmento de estudantes foi o de maior alcance, por representar a grande população da escola. Foram entrevistados 400 (quatrocentos) estudantes nos turnos da manhã, tarde e noite. No perfil do segmento destacaram-se os seguintes aspectos: $24,5 \%$ estavam matriculados na $7^{\mathrm{a}}$ série, $33,5 \%$ estavam vinculado à escola pelo tempo que varia entre 1 a 3 anos. Em relação à faixa etária, observou-se que 28,2\% encontrava-se entre 14 e 16 anos, seguidos por 27,5\% entre 16 e 18 anos, isto é, grupo formado por adolescentes capazes de emitir uma percepção sobre fatos, relações e interações grupais.

O quadro geral que identifica os gestores das 12 (doze) escolas onde se desenvolveu a pesquisa apresenta o seguinte perfil: todos têm nível superior e 10 (dez) têm especialização. 5 (cinco) deles estão à mais de 12 (doze) anos na escola, 2 (dois) têm mais de um ano e os demais, encontram-se neste intervalo. A maioria é do sexo feminino, 5 (cinco) 
têm mais de 50 anos de idade, 2 (dois) têm mais de 30 e os demais encontram-se no intervalo.

A metodologia adotada para abordar o problema da pesquisa foi o estudo de caso, justificado no fato de ser uma metodologia orientada para abordar temas das ciências sociais, por tratar-se de uma questão do tipo "como", e porque o foco do problema se encontra em fenômeno contemporâneo, inserido em um contexto da vida real, e ainda, por não haver exigência de controle sobre os eventos, e sim, a preocupação com a apresentação justa e rigorosa dos dados empíricos, em todas as fases de planejamento, coleta, análise e apresentação de resultados.

\section{Revisão de Literatura}

No contexto das mudanças de paradigmas, a gestão participativa vem assumindo uma importância cada vez maior no cenário das relações no mundo contemporâneo. A literatura sobre a gestão participativa na sociedade de modo geral e de modo específico, na gestão da organização escolar, destaca o pensamento de teóricos e pesquisadores assegurando o suporte teórico da pesquisa empírica.

\subsection{A Administração Participativa na Teoria Organizacional}

A administração participativa classificada como uma das teorias modernas de gestão defende a democracia das relações sociais, 0 desenvolvimento da consciência da classe trabalhista, a elevação do nível educacional, a complexidade das empresas modernas, a velocidade das mudanças e a intensificação das comunicações. "De maneira abrangente, a administração participativa é uma filosofia ou doutrina que valoriza a participação das pessoas no processo de tomar decisões sobre a administração das organizações." (MAXIMIANO, 2002, p. 462).

A definição de Maximiano (2002), conforme explicação do próprio autor, considera que: nos modelos convencionais da administração não comporta a ação de participação dos trabalhadores, mas a de manutenção de sua alienação em relação ao controle de seu próprio trabalho e à gestão da organização. Esta alienação desperdiça o potencial intelectual das pessoas, ao passo que, o modelo da participação aproveita esse potencial, contribuindo para aumentar a qualidade das decisões e da administração, a satisfação e a motivação das pessoas, aprimorando a decisão e o clima organizacional.
Para Lerner (1991), a administração participativa é a forma moderna de reduzir conflitos, aumentar a produtividade e alcançar a excelência empresarial com a distribuição de resultados. Propôs um programa participativo de organização com o objetivo de implantar uma metodologia de trabalho abrangente de todos os departamentos centrais e unidades, para obter uma permanente, integrada e evolutiva eficácia de desempenho para força de trabalho.

Para Mendonça (1987), "a participação constitui um dos mais importantes temas da prática e da teoria organizacionais, seja como conceito central, seja como tecnologia social". O conceito central concebe a participação como a variável que define e indica o que e como alguém faz algo numa organização. É também a forma de conhecer a dimensão ideológica embutida nas práticas e teorias organizacionais.

Enquanto tecnologia social, Mendonça (1987) considera a participação como estratégia para a formulação de objetivos, tomada de decisão, resolução de problemas e mudanças organizacionais, sendo uma abordagem gerencial amparada na motivação. A participação empregada nas duas formas reduz a alienação, aumenta 0 moral, assegura eficiência, produtividade e estimula a harmonia. O pensamento do autor defende o homem como um ser essencialmente capaz de produzir o mundo e a si mesmo, sendo seu trabalho para a liberdade, criação e realização.

\subsection{A Participação no Fenômeno Social e Político}

A participação tem sido evocada em diversos setores da sociedade. A mídia utiliza seu apelo em campanhas publicitárias com diversos objetivos, sendo o tema, fonte de interesse em várias atividades de diferentes grupos e empreendimentos.

Bordenave (1983) questiona as causa da intensificação dos processos participativos considerando que: a participação está na ordem do dia, devido ao descontentamento geral com a marginalização do povo em assuntos que interessam a todos e que são decididos por poucos; que a participação pode se implantar tanto com objetivos de liberação e igualdade como para a manutenção de uma situação de controle de muitos por alguns; que 0 interesse pela participação no setor progressista é uma forma de garantir a democracia e mecanismo para a resolução de conflitos considerados insolúveis pelo indivíduo isoladamente. $\mathrm{O}$ autor refere-se à participação como "necessidade fundamental do 
ser humano" e reconhece-a meio de interação com outros homens, auto-expressão, pensamento reflexivo, prazer de criar coisas e valorização das pessoas.

Quanto ao modo de participação, refere-se à microparticipação que se dá em associações voluntárias entre pessoas que não pretendem tirar benefícios unicamente pessoais, enquanto que na macroparticipação as pessoas intervêm nos processos dinâmicos que constituem a própria sociedade, como a produção dos bens materias e culturais, a administração e usufruto dos mesmos. Para o autor, uma população é verdadeiramente participante quando não apenas produz, mas usufrui e toma parte na gestão. Considera questão preponderante no processo de participação, o grau de controle e o nível de importância das decisões e ilustra os graus de participação com o esquema na figura 1:

Figura 1 - Os Graus e Níveis de Participação

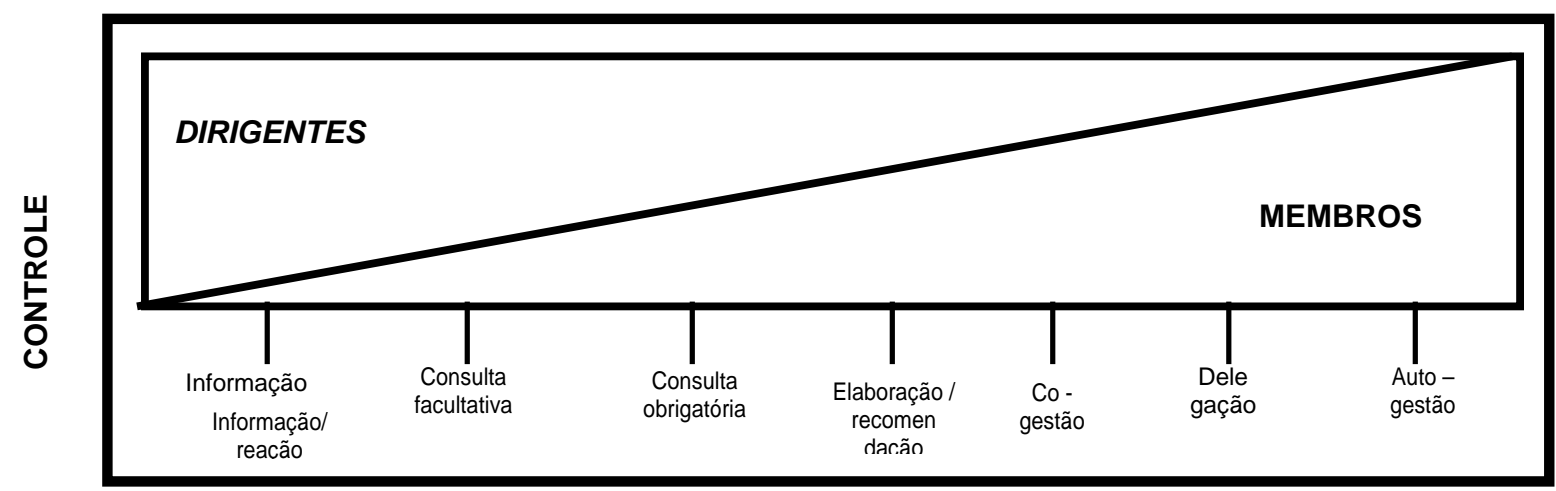

Fonte: Bordenave (1983, p. 30).

O diagrama de Bordenave (1983) expressa que o menor nível de participação encontra-se na informação, onde por vezes, os membros que recebem informação dos dirigentes, esboçam alguma reação às informações recebidas. O segundo grau de participação, a consulta facultativa, ocorre quando, e se, a administração quiser consultar os subordinados para resolver algum problema. Quando a consulta é obrigatória, o grau de participação aprofunda-se, mesmo quando a decisão final fica com os dirigentes. No terceiro grau de participação a consulta é obrigatória, o quarto grau ocorre quando os subordinados elaboram e recomendam procedimentos, cabendo a administração aceitar ou rejeitar as mesmas. O quinto grau se evidencia quando a administração compartilha as decisões, o sexto, quando os subordinados têm autonomia em alguns campos definidos e delimitados pelos administradores.

Finalmente, o sétimo e mais alto grau de participação na escala de Bordenave (1983) encontra-se na autogestão, onde o grupo tem autonomia para determinar seus objetivos, os meios e os controles, e administradores e administrados eliminam suas distâncias e diferenças.

O autor aponta as qualidades pessoais dos membros de um grupo, a natureza do problema que se pretende resolver, a filosofia da instituição ou do grupo e a própria estrutura social, como condicionantes capazes de determinar, circunstancialmente, o grau, o nível e a qualidade da participação. Sendo a participação uma característica social do homem, Bordenave (1983) defende que ele precisa aprender a participar nas relações em diferentes grupos e na escola. A função educativa da participação é de extraordinária relevância no sentido de "preparar o povo para assumir o governo como algo próprio de sua soberania, tal como está escrito na Constituição" Bordenave (1983, p. 56).

Aponta como grave deficiência da democracia liberal, pretender que os cidadãos exerçam a macroparticipação sem a aprendizagem da microparticipação. "A participação escolacomunidade constitui um laboratório vivo onde os futuros cidadãos aprendem a difícil arte da convivência democrática" (BORDENAVE, 1983, p. 61). O autor reconhece que a escola pública está procurando ser mais participativa. Neste intento, ela traça caminhos complementares em dois sentidos: o da participação da comunidade na escola e o da participação da escola na comunidade.

Para Demo (2001), o problema da participação só pode ser colocado tendo a questão da política social como uma das suas faces e que a idéia de participação pronta não existe, mas somente na medida de sua própria conquista. Diz ainda que a 
falta de espaço de participação não é um problema em si, mas ponto de partida que pressupõe compromisso nas ações. Apresenta a participação também como outra forma de poder, tanto na comunidade, da parte do técnico e do intelectual. Aponta o planejamento participativo e a educação como formação à cidadania, como canais de participação.

A) Planejamento Participativo - Para Demo (2001), o planejamento participativo, desenvolvido a partir dos componentes básicos: autodiagnóstico, ação e organização, podem ser os elementos capazes de produzirem iniciativas a nível local. Adverte para a necessidade de olhar com cuidado o lado do técnico e o lado da comunidade. Do técnico, chama a atenção para a natureza real da participação que não funciona sob decreto. Reconhece que a formulação científica no tratamento do fenômeno participativo, pode conter resquícios de resistência à política. Assim, a qualidade técnica demanda de cuidados nos planos teóricos e metodológicos, devendo fugir das posturas de purismo e de populismo, no sentido de não considerar o técnico como manipulador, nem superestimar seu saber como determinante e irredutível.

Da parte da comunidade, Demo (2001) aponta para a mudança da postura de recebimento de favores, para a de reivindicação de direitos e soluções dos problemas, considerando-se como parte da solução. Nesta postura, a mudança se daria de população-alvo para sujeito principal das políticas.

Apesar de todos os senões e cautelas, Demo (2001) assegura que o planejamento participativo é possível, e que nem todo processo participativo é revolucionário, e o reacionário, avesso ao poder do Estado, incorre no equívoco da banalização de uma ilusão de poder, se não estiver organizado e identificado com a cultura da comunidade.

B) Educação como Formação à Cidadania Enquanto instrumento de participação política, a educação é percebida como a maior das virtudes. Sua função insubstituível recai na ordem política, enquanto condição à participação, vista como incubadora da cidadania e processo formativo. Afirma que o projeto de cidadania se organiza a partir dos componentes: formação, participação, autopromoção, autodefinição, sujeito social, direitos e deveres, democracia, liberdade, igualdade, comunidade, informação, saber e habilidades. Estas noções apresentadas por Demo (2001), podem ser compreendidas como elementos norteadores da construção de um currículo para uma educação cidadã.
Acrescenta que processos educativos que não levam à participação são em si deseducativos por privilegiar estruturas impositivas que transformam o profissional manipulador da educação no centro do processo educativo, em vez de colocar aí, o educando. O aspecto comunitário da educação é o cerne para a cidadania, e parte sempre da potencialidade e criatividade do educando e sua família, e é o que the confere legitimidade.

\subsection{Gestão Participativa na Educação}

$\mathrm{Na}$ gestão educacional, Lück, (2004) enriquecem a discussão sobre a mudança dos termos administração e gestão, por compreendêlos bem distintos no campo da educação. Reforçam que não se trata apenas de simples substituição terminológica, baseada em considerações semânticas, mas, da proposição de um novo conceito de organização educacional. Segundo as autoras, a ótica da gestão não elimina a da administração educacional, mas a supera, resignificando-a e redimensionando-a, razão porque procedimentos próprios da administração controle de recursos, de tempo, planejamento, estratégias, etc. - permanecem fazendo parte do trabalho dos dirigentes de organizações de ensino. $\mathrm{Na}$ prática, a superação da administração pela gestão, demanda um planejamento de caráter participativo

O novo paradigma exige novas compreensões para a função de diretor escolar, formuladas em proposta de trabalho participativo, e o compromisso de assumir o papel de articulador das ações entre os diversos segmentos escolares, abrir espaços para discussão coletiva das questões pertinentes ao todo da escola. A mudança do estilo de direção, descentralizando e compartilhando decisões, expressa um avanço e um desafio reais.

A proposição de gestão participativa que contém em seu bojo a essência da autonomia, não deve eliminar a vinculação da unidade de ensino com o sistema educacional que a sustenta. A autonomia é limitada, uma vez que ações que promovam a força do conjunto, só são possíveis, mediante uma coordenação geral que observe e acompanhe criticamente os pressupostos e requisitos legais, sem abandonar a postura necessária da flexibilidade e do bom senso, em relação à participação na formação da cidadania.

Para Lück (2004), "a gestão participativa é normalmente entendida como uma forma regular e significante de envolvimento dos funcionários de uma organização no seu processo decisório". No contexto escolar, esse conceito envolve também 
professores, pais, alunos e representantes da comunidade. Contudo, é a legitimidade do envolvimento das pessoas, que, segundo as autoras, os resultados da participação serão positivos ou negativos. Os resultados negativos referem-se a práticas onde participantes são convidados a verbalizar sobre questões anteriormente decididas, como estratégia de legitimação.

Segundo Lück (2004), a participação caracteriza-se por uma força de atuação consciente, pela qual os membros de uma comunidade assumem o poder de exercer influência sendo este poder resultante da competência, da vontade de compreender, decidir e agir em torno de questões que afetam a comunidade. Contudo, da falta de consciência do poder de participação decorrem resultados negativos para as pessoas que constituem 0 ambiente escolar, como também para a organização social.

As autoras advertem que a participação, no sentido dinâmico de inter-apoio e integração, visando construir uma realidade mais significativa, não se constitui em prática comum nas escolas e que a compreensão do significado de participação não está clara nem mesmo para o dirigente das instituições de ensino. Consideram também que no domínio das inovações educacionais (currículo, avaliação, planejamento, ensino) existe um grande espaço para experimentações. Contudo, no domínio das inovações organizacionais, não se verifica a flexibilidade necessária para que a escola se reestruture internamente. $\mathrm{Na}$ defesa de um programa de atividades para adoção da participação, apresentam o que denominam passos iniciais e difíceis, no Quadro 2.

Quadro 2 - Características da Gestão Participativa

- Compartilhamento da autoridade

- Delegação de poder

- Responsabilidades assumidas em conjunto

- Valorização e mobilização da sinergia da equipe

- Canalização de talentos e iniciativas em todos os segmentos da organização

- Compartilhamento constante e aberto de informações.

Fonte LÜCK (2002, p. 31).

Nos passos iniciais, verifica-se uma síntese das características da gestão escolar, levando à clara compreensão de que a gestão participativa requer a preparação da comunidade escolar e do próprio sistema de educação. Com vistas à coordenação participativa no trabalho escolar, sugerem critérios profissionais relevantes para um processo seletivo e relacionam habilidades necessárias na área administrativa (planejamento, orçamento, organização, etc.), e na área relacional (comunicação, negociação, avaliação e feedback, etc.). Dentre os critérios, as autoras apontam a capacidade "de trabalhar com outros indivíduos da comunidade escolar, sem perder a visão do potencial que esta comunidade tem para estimular seu próprio crescimento e progresso". (LÜCK, 2004, p. 90). As contribuições de Lück et al (2004) não chegam desacompanhadas de uma consistente finalidade política, ou seja, a construção da gestão participativa na escola, profundamente interligada aos ideais de uma sociedade democrática e na formação da cidadania.

\section{Resultados}

Os resultados mostram o que foi obtido na pesquisa, ilustrado com quadros, tabelas e gráficos. A síntese está organizada em seis partes, que alcançam os objetivos da pesquisa, destacando os aspectos mais expressivos na percepção dos diferentes segmentos. O quadro 3 apresenta os resultados sobre as principais realizações da Gestão Escolar na Prática da Gestão Participativa, segundo os próprios gestores. 
Quadro 3 - Síntese das Principais Respostas dos Gestores

\begin{tabular}{|c|c|}
\hline CRITÉRIO & SÍNTESE DAS RESPOSTAS \\
\hline $\begin{array}{l}\text { 1. Quais são, na } \\
\text { prática, as suas } \\
\text { principais ações que } \\
\text { caracterizam o } \\
\text { compartilhamento } \\
\text { da autoridade do } \\
\text { diretor? }\end{array}$ & $\begin{array}{l}\text { - Ações de responsabilidade sem autoritarismo, descentralização, aceitação de sugestões, } \\
\text { relação e interação com a comunidade, ouvir pais, reunião de pais, cumprimento de } \\
\text { responsabilidades, decisões em conjunto e reunir o Conselho Escolar. }\end{array}$ \\
\hline $\begin{array}{l}\text { 2. Em quais } \\
\text { circunstâncias } \\
\text { ocorre a delegação } \\
\text { de poder na escola? }\end{array}$ & $\begin{array}{l}\text { - Na participação efetiva e nas decisões do Conselho Escolar, no compartilhamento com todos } \\
\text { que fazem a escola, para que a escola não sofra ação de continuidade quando o diretor se } \\
\text { ausentar, nos momentos de planejamento, quando há necessidade de estar ausente, quando o } \\
\text { grupo gestor (diretor, vice-diretor e secretária) reveza horários e cada um desses membros pode } \\
\text { resolver sobre qualquer assunto na escola no seu horário. }\end{array}$ \\
\hline $\begin{array}{l}\text { 3. Quais as } \\
\text { responsabilidades } \\
\text { que são assumidas } \\
\text { em conjunto com o } \\
\text { Conselho Escolar? }\end{array}$ & $\begin{array}{l}\text { - A resolução de problemas disciplinares, os aspectos pedagógicos, os aspectos administrativo e } \\
\text { financeiro, a utilização de recursos financeiros, a prestação de contas, a tomada de alguma } \\
\text { decisão importante na escola, as decisões de compras e prestações de verbas, resolução de } \\
\text { problemas, decisões mais abrangentes, decisões sobre as prioridades e benefícios da escola. }\end{array}$ \\
\hline $\begin{array}{l}\text { 4. Como a direção } \\
\text { expressa a } \\
\text { valorização e } \\
\text { mobilização da } \\
\text { sinergia da equipe? }\end{array}$ & $\begin{array}{l}\text { - De uma maneira democrática, motivando a participação de todos que fazem parte da } \\
\text { comunidade escolar, construindo e participando de todo o processo de mobilização da equipe, } \\
\text { através do incentivo ao compromisso, em reuniões, deixando clara a importância de cada um } \\
\text { para o grupo, valorizando o trabalho de cada profissional, com um ambiente propício à } \\
\text { participação, sempre procurando ressaltar a colaboração de cada um, com compromisso e } \\
\text { unidade, diálogo sobre a importância de unirmos em busca do interesse em comum, sempre } \\
\text { motivando a participar e se envolver no projeto de revitalização da escola. }\end{array}$ \\
\hline $\begin{array}{l}\text { 5. Como e quando as } \\
\text { informações são } \\
\text { compartilhadas? }\end{array}$ & $\begin{array}{l}\text { - Nos sábados de planejamento e intervalos, nas reuniões periódicas, reuniões de planejamento, } \\
\text { reuniões de pais, em reuniões pedagógicas, nos encontros mensais, reuniões bimestrais com os } \\
\text { pais, sempre que é necessário, na sala dos professores, em reuniões e na hora do recreio. }\end{array}$ \\
\hline
\end{tabular}

Fonte: Banco de dados da pesquisa.

No quadro 3, verifica-se que a principal ação da direção, utilizada para o compartilhamento da autoridade na escola, foi a reunião de pais. Segundo os gestores pesquisados, a delegação de poder ocorre quando as atividades do gestor são muitas e o tempo é pouco e quando há necessidade de estarem ausentes. Dentre as responsabilidades compartilhadas com o Conselho Escolar (CE) a maior referência foi ao nível financeiro. De modo geral, observou-se na maioria das escolas, que a direção adota procedimentos de caráter democrático, capazes de motivar a participação.

As respostas coletadas sobre canalização de talentos e iniciativas foram sintetizadas nas afirmativas mais comuns apresentadas pelos segmentos pesquisados, chegando-se ao resultado do Quadro 4:

Quadro 4 - Respostas mais freqüentes por segmento.

\begin{tabular}{|l|l|}
\hline \multicolumn{1}{|c|}{ SEGMENTO } & \multicolumn{1}{c|}{ PERCEPÇÃo } \\
\hline ESTUDANTES & Valorização das habilidades no esporte, feira cultural e esportes \\
\hline PROFESSORES & $\begin{array}{l}\text { Reconhecimento da sua importância no planejamento e elogio nas reuniões de } \\
\text { professores de pais e Conselho Escolar }\end{array}$ \\
\hline ESPECIALISTAS & Valorização de projetos através de premiação \\
\hline FUNCIONÁRIOS & $\begin{array}{l}\text { Valorização do trabalho de cada um. Participação em todas as ações da escola, } \\
\text { somando nas atividades culturais e reconhecimento do papel desenvolvido por cada } \\
\text { um e destaque pela dedicação na função de cada }\end{array}$ \\
\hline PAIS & $\begin{array}{l}\text { Estímulo à participação, contribuição e envolvimento em ações dentro da escola, } \\
\text { nas atividades no dia a dia da escola e nas reuniões. }\end{array}$ \\
\hline
\end{tabular}

Fonte: Banco de dados da pesquisa.

Em relação às informações, foi verificado em todas as escolas pesquisadas, que elas são compartilhadas de modo sistemático em reuniões formais e de modo assistemático, nos intervalos, na hora do recreio e no quadro de avisos. 
4.1 A Percepção dos Servidores, Estudantes e Pais sobre as Atitudes da Gestão

A pesquisa revelou que $49,4 \%$ dos servidores concordaram que a direção assume responsabilidades com o CE e 25,9\% concordaram em parte, conforme mostra a tabela 1.

Tabela 1 - Atitudes da Gestão/Percepção dos Servidores

AFIRMATIVAS

A autoridade do diretor é compartilhada com o Conselho Escolar A direção da escola delega poder ao Conselho Escolar

A direção da escola assume resposanbilidades com o Conselho Escolar

A diretoria valoriza e mobiliza a sinergia da equipe

A direção da escola canaliza os talentos e iniciativas em todos os segmentos da escola PERCEPÇÃO DOS ESTUDANTES

\section{AFIRMATIVAS}

A autoridade do diretor é compartilhada com o Conselho Escolar

A direção da escola delega poder ao Conselho Escolar

A direção da escola assume resposanbilidades com o Conselho

Escolar

A diretoria valoriza e mobiliza a sinergia da equipe

A direção da escola canaliza os talentos e iniciativas em todos os

\section{PERCEPÇÃO DOS PAIS}

AFIRMATIVAS

A autoridade do diretor é compartilhada com o Conselho Escolar

A diretoria mobiliza a participação dos pais

A direção da escola canaliza os talentos e iniciativas dos pais para a melhoria da escola
A direção compartilha as informações de modo aberto e constante segmentos da escola

\begin{tabular}{|c|c|c|c|}
\hline NNC & $\mathrm{CCP}$ & $\mathrm{CCC}$ & $\mathrm{CCM}$ \\
\hline $10,9 \%$ & $32,2 \%$ & $39,7 \%$ & $15,1 \%$ \\
\hline $9,6 \%$ & $31,4 \%$ & $43,9 \%$ & $12,6 \%$ \\
\hline $7,9 \%$ & $25,9 \%$ & $49,4 \%$ & $15,9 \%$ \\
\hline $12,1 \%$ & $35,1 \%$ & $37,2 \%$ & $14,6 \%$ \\
\hline $14,2 \%$ & $38,9 \%$ & $36,8 \%$ & $10,0 \%$ \\
\hline $10,5 \%$ & $31,4 \%$ & $37,2 \%$ & $19,2 \%$ \\
\hline NNC & CCP & $\mathrm{CCC}$ & $\mathrm{CCM}$ \\
\hline $53,8 \%$ & $27,3 \%$ & $10,8 \%$ & $5,5 \%$ \\
\hline $21,3 \%$ & $49,3 \%$ & $19,3 \%$ & $6,5 \%$ \\
\hline $19,3 \%$ & $45,3 \%$ & $21,5 \%$ & $11,5 \%$ \\
\hline $22,8 \%$ & $29,0 \%$ & $34,0 \%$ & $12,8 \%$ \\
\hline $39,3 \%$ & $24,8 \%$ & $26,8 \%$ & $7,2 \%$ \\
\hline NNC & $\mathrm{CCP}$ & $\mathrm{CCC}$ & $\mathrm{CCM}$ \\
\hline $28,1 \%$ & $46,9 \%$ & $9,4 \%$ & $9,4 \%$ \\
\hline $0,0 \%$ & $0,0 \%$ & $0,0 \%$ & $87,5 \%$ \\
\hline $0,0 \%$ & $0,0 \%$ & $9,4 \%$ & $81,3 \%$ \\
\hline
\end{tabular}

LEGENDA: NC = Não concordo, CP = Concordo em parte, CC = Concordo e CM = Concordo muito.

Fonte: Banco de Dados da Pesquisa.
O resultado expresso na tabela 1 permite afirmar que a maior parte dos servidores reconhece a coresponsabilidade da direção com o CE.

Verifica-se no que tange à delegação de poder, que $43,9 \%$ dos servidores concorda que a direção delega poder aos membros do $C E$ e que as atitudes do gestor caracterizam-se mais por assumir responsabilidades com o CE, do que delegar poder a este órgão. A diferença percentual entre as duas atitudes foi praticamente insignificante. Dos 239 servidores pesquisados, $39,7 \%$ concorda que a autoridade do diretor é compartilhada com o CE.

Verificou-se que $53,8 \%$ dos estudantes respondeu não concordo a afirmativa "A autoridade do diretor é compartilhada com o CE" e 49,3\% assinalou concordo em parte que "A direção da escola delega poder aos membros do CE". 45,3\% dizem concordo em parte que a direção da escola assume responsabilidades com o CE e 39,3\% não concorda que a direção canaliza os talentos e iniciativas em todos os seus segmentos. A percepção dos estudantes, sobre ações de canalização de seus talentos, converge com a percepção dos servidores, que não reconhecem nesta atitude, uma marca da gestão, o que leva à compreensão da não universalização desta ação na escola, reconhecendo sua existência em proporções restritas.

Chamou a atenção o fato de $87,5 \%$ dos pais terem afirmado concorda muito com a afirmativa "a direção valoriza e mobiliza a participação dos pais". $81,3 \%$ concordam muito com a afirmativa "a direção da escola canaliza os talentos e iniciativas dos pais para a melhoria da escola". Verificou-se a existência de percepções divergentes entre os pais de alunos e os próprios estudantes, sobre a mesma situação, enquanto a percepção dos servidores, registra menor distância com o que dizem os gestores.

\subsection{Os Procedimentos Efetivos na Dinâmica da Relação Escola-Comunidade}

Dentre os servidores, $70,3 \%$ não concorda com a afirmativa "os pais de alunos participam de discussão sobre calendário escolar"; 58,6\% não concorda que "os pais de alunos participam de 
discussão sobre trabalhos práticos e pesquisas a serem realizados"; 50,6\% concorda em parte com a afirmativa de que "os pais de alunos participam da vida da escola como um todo". Verificou-se também que 40,2\% dos servidores não concorda com a afirmativa que diz "os pais de alunos participam de reuniões sobre conteúdos escolares".

No segmento de estudantes, destacou-se que: $79,3 \%$ dos estudantes não concorda que seus pais participam de discussões sobre trabalhos caracterizados como excurções, aulas de campo, passeios, trabalhos de pesquisa para apresentação, etc. ou seja, atividades práticas que passam por discussão e planejamento específico.

Nas respostas dos pais sobre a relação da escola com a comunidade, destaca-se a ênfase na afirmativa: "eu participo de reuniões sobre o ensino e a aprendizagem", onde $75 \%$ concorda muito, seguida dos $68,8 \%$ que também concorda muito com a afirmativa "eu sou informado sobre o ensino e aprendizagem". Verifica-se que o expressivo resultado dos pais, diz concordar muito tanto na participação/planejamento, tanto com a informação, entra em contradição com a percepção dos alunos sobre a participação de seus pais nas questões da organização escolar, onde $79,3 \%$ dos alunos respondeu não concordo.

Os pais de alunos com mais propriedade puderam falar sobre a relação da escolacomunidade por serem os usuários residentes no entorno. A pesquisa revelou que à afirmativa "a escola participa da vida cultural da comunidade", $75 \%$ respondeu que não concorda e "a escola reúne representantes da comunidade na busca de solução de problemas", onde $68,8 \%$ respondeu que não concorda, conforme verifica-se na tabela 2 .

\begin{tabular}{|c|c|c|c|c|c|}
\hline & Percepção dos Servidores & NNC & CCP & $\mathrm{CCC}$ & $\mathrm{CCM}$ \\
\hline \multirow{5}{*}{ 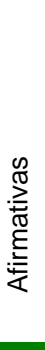 } & $\begin{array}{l}\text { Os pais de alunos participam de reuniões sobre conteúdos } \\
\text { escolares }\end{array}$ & $40,2 \%$ & $31,8 \%$ & $20,9 \%$ & $7,1 \%$ \\
\hline & Os pais de alunos participam da vida da escola como um todo & $21,8 \%$ & $50,6 \%$ & $23,0 \%$ & $2,5 \%$ \\
\hline & $\begin{array}{l}\text { Os pais de alunos participam de discussão sobre calendário } \\
\text { escolar }\end{array}$ & $70,3 \%$ & $22,2 \%$ & $6,7 \%$ & $0,8 \%$ \\
\hline & $\begin{array}{l}\text { Os pais de alunos participam de discussão sobre trabalhos práticos } \\
\text { e pesquisas a serem realizadas }\end{array}$ & $58,6 \%$ & $31,8 \%$ & $7,1 \%$ & $0,0 \%$ \\
\hline & $\begin{array}{l}\text { Os pais de alunos são informados sobre as atividades da escola } \\
\text { como um todo }\end{array}$ & $15,5 \%$ & $38,9 \%$ & $30,1 \%$ & $15,5 \%$ \\
\hline \multirow{5}{*}{ 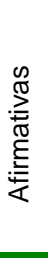 } & Percepção dos Estudantes & NNC & CCP & $\mathrm{CCC}$ & $\mathrm{CCM}$ \\
\hline & Os meus pais participam de reuniões sobre conteúdos escolares & $68,0 \%$ & $11,8 \%$ & $10,0 \%$ & $5,8 \%$ \\
\hline & Os meus pais participam da vida da escola como um todo & $59,5 \%$ & $26,8 \%$ & $7,2 \%$ & $2,3 \%$ \\
\hline & $\begin{array}{l}\text { Os meus pais participam de discussão sobre trabalhos práticos e } \\
\text { pesquisas a serem feitas }\end{array}$ & $79,3 \%$ & $8,8 \%$ & $4,5 \%$ & $3,0 \%$ \\
\hline & $\begin{array}{l}\text { Os pais de alunos são informados sobre as atividades da escola } \\
\text { como um todo }\end{array}$ & $28,7 \%$ & $30,0 \%$ & $24,5 \%$ & $12,5 \%$ \\
\hline \multirow{3}{*}{ 苞 } & Percepção dos Pais & NNC & СCP & $\mathrm{CCC}$ & $\mathrm{CCM}$ \\
\hline & Eu participo de reuniões sobre o ensino e aprendizagem & $12,5 \%$ & $12,5 \%$ & $0,0 \%$ & $75,0 \%$ \\
\hline & Eu sou informado sobre o ensino e a prendizagem & $9,4 \%$ & $6,3 \%$ & $15,6 \%$ & $68,8 \%$ \\
\hline
\end{tabular}

LEGENDA: NC = Não concordo, CP = Concordo em parte, CC = Concordo e CM = Concordo muito Fonte : Banco de dados da pesquisa.

Em entrevista de aprofundamento, cerca de $40 \%$ dos pais afirmam que "A direção procura conhecer a comunidade no entorno da escola", confirmando também que a participação da escola na comunidade é inexistente, por outro lado, os pais apresentam-se como colaboradores voluntários na resolução dos problemas na escola.

\subsection{A Particiação dos Servidores no Planejamento, na Execução e no Usufruto}

O segmento servidores mostrou que $81,6 \%$ não concordaram com a afirmativa: "Eu participo das tomadas de decisão do Distrito de Educação da SER II", e a coluna NC (não concordo) de maior evidência, revelando pouca participação no aspecto de planejamento, confirmada com os ínfimos percentuais da coluna CM.

No critério execução, constatou-se a seguinte situação: $41,4 \%$ dos servidores concorda com a 
afirmativa: "Eu me sinto comprometido com a solução de problemas". A observação revelou que existe uma disposição geral com a efetiva resolução de problemas. No critério usufruto, verificou-se que $59,4 \%$ não concorda com a afirmativa: "Eu usufruo dos esportes", sendo o espaço físico considerado o maior usufruto com apenas 39,7\% respostas concordo.

A percepção dos servidores entrevistados revelou que em relação ao planejamento, encontram-se num grau muito baixo na escala de Bordenave, localizando-se entre a informação e a consulta facultativa. No critério Execução, a maioria das escolas encontra-se no grau de elaboração/recomendação e em menor quantidade, no grau de consulta facultativa. Quanto ao usufruto, os resultados se identificam com grau de informação. A tabela 3 apresenta o grau de participação de servidores.

Tabela 3: PERCEPÇÃO DOS SERVIDORES

\begin{tabular}{|c|c|c|c|c|c|}
\hline \multirow{5}{*}{ 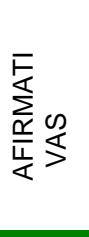 } & $\begin{array}{l}\text { PLANEJAMENTO } \\
\text { Eu participo da formulacão das políticas da SEDAS }\end{array}$ & $\begin{array}{l}\text { NNC } \\
75.3 \%\end{array}$ & $\begin{array}{l}\text { CCP } \\
19.2 \%\end{array}$ & CCC & CCM \\
\hline & $\begin{array}{l}\text { Eu participo das diretrizes da Coordenadoria } \\
\text { de Educação }\end{array}$ & $78,7 \%$ & $15,5 \%$ & $5,0 \%$ & $0,8 \%$ \\
\hline & Eu participo das tomadas de decisão do Distrito de Educação & $81,6 \%$ & $13,8 \%$ & $2,1 \%$ & $1,3 \%$ \\
\hline & Eu participo do planejamento estratégico & $64,4 \%$ & $28,5 \%$ & $5,4 \%$ & $1,7 \%$ \\
\hline & Eu participo do planejamento operacional & $63,2 \%$ & $27,6 \%$ & $8,8 \%$ & $0,0 \%$ \\
\hline \multirow{6}{*}{ 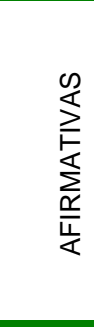 } & EXECUÇÃO & NNC & $\mathrm{CCP}$ & $\mathrm{CCC}$ & $\mathrm{CCM}$ \\
\hline & $\begin{array}{l}\text { Eu tenho poder na minha área de trabalho para tomar decisões } \\
\text { relacionadas às situações emergenciais da dinâmica do cotidiano }\end{array}$ & $18,0 \%$ & $30,1 \%$ & $32,2 \%$ & $19,7 \%$ \\
\hline & $\begin{array}{l}\text { Eu tenho poder na escola como um todo, para tomar decisões } \\
\text { relacionadas às situações emergenciais do cotidiano }\end{array}$ & $33,9 \%$ & $31,4 \%$ & $27,2 \%$ & $5,9 \%$ \\
\hline & Eu me sinto representado no Conselho Escolar & $27,2 \%$ & $31,8 \%$ & $25,9 \%$ & $15,1 \%$ \\
\hline & Eu me sinto comprometido com a solução de problemas & $8,8 \%$ & $25,5 \%$ & $41,4 \%$ & $22,6 \%$ \\
\hline & $\begin{array}{l}\text { Eu me sinto responsável pelos resultados obtidos pela escola como } \\
\text { um todo }\end{array}$ & $11,7 \%$ & $38,5 \%$ & $33,5 \%$ & $16,3 \%$ \\
\hline \multirow{5}{*}{ 㐫 } & USUFRUTO & NNC & $\mathrm{CCP}$ & $\mathrm{CCC}$ & $\mathrm{CCM}$ \\
\hline & Eu usufruo do conhecimento produzido pela escola & $15,1 \%$ & $35,6 \%$ & $34,7 \%$ & $13,8 \%$ \\
\hline & Eu usufro do espaço físico & $12,1 \%$ & $33,9 \%$ & $39,7 \%$ & $13,4 \%$ \\
\hline & Eu usufro da tecnologia & $34,3 \%$ & $32,6 \%$ & $23,0 \%$ & $8,8 \%$ \\
\hline & Eu usufro dos esportes & $59,4 \%$ & $19,7 \%$ & $14,6 \%$ & $4,6 \%$ \\
\hline en & Eu usufro da cultura e arte & $29,3 \%$ & $38,1 \%$ & $26,8 \%$ & $5,0 \%$ \\
\hline
\end{tabular}

LEGENDA: NC = Não concordo, $\mathrm{CP}=$ Concordo em parte, $\mathrm{CC}=$ Concordo e CM = Concordo muito.

Fonte: Banco de dados da pesquisa.

\subsection{A participação de Estudantes e Pais no Planejamento}

A pesquisa verificou que $67 \%$ dos estudantes, dizem não concordo com a afirmativa: "Eu me sinto responsável pelos resultados obtidos pela escola como um todo" e $64,3 \%$, não concorda com a afirmativa: "Eu me sinto comprometido coma solução de problemas". Verificou-se entre os estudantes o apartheid entre as noções de fazer parte e tomar parte. Segundo Bordenave (1983), é uma grave deficiência pretender que os cidadãos exerçam a macroparticipação sem que necessariamente passem pela microparticipação. Assim como os servidores, os estudantes estão num grau muito baixo de participação entre a informação e a consulta facultativa.

As respostas dos pais dizem concordar muito com a afirmativa: "Eu participo das atividades da escola como um todo" (50\%). Também 46,9\% concordam muito com a afirmativa "Eu me sinto representado no Conselho Escolar". A resposta dos pais torna-se curiosa pelo fato do segmento ser mais distante do cotidiano da escola. O conjunto das percepções dos pais aponta para o grau de participação identificada por Bordenave (1983), como consulta facultativa.

\subsection{A Participação no Usufruto segundo a percepção dos Estudantes e Pais}

Chamou a atenção o fato de 56,8\% dos estudantes responderem NC para a afirmativa "eu usufruo dos esportes" Em entrevista, alguns estudantes falaram: "não tem time, não tem treinador, falta equipamento, não tenho tempo, trabalho no outro turno". Os argumentos alegados para o não usufruto do esporte foi ainda mais intensa entre estudantes do noturno, onde foi constatado que a participação como usufruto no esporte não faz parte da realidade. Questionados 
sobre o usufruto do conhecimento produzido pela escola, as respostas dos estudantes procurava explicar a necessidade de aprender outras "coisas" fora da escola, fazer cursinhos e cursos profissionalizantes. No gráfico 1 , pode-se verificar a ilustração das respostas dos segmentos estudantes e pais, no critério usufruto.

Gráfico 1: Respostas Não Concordo" de estudantes e pais, sobre o critério usufruto.

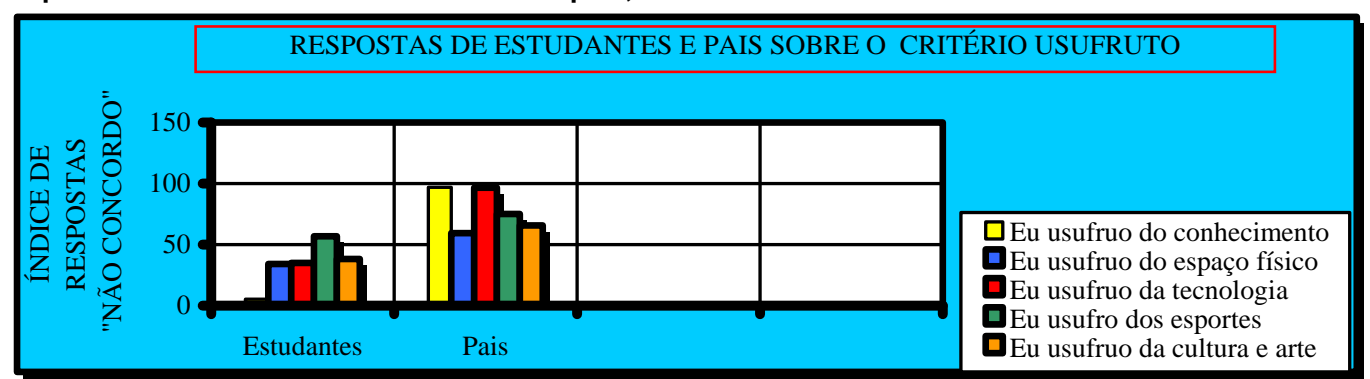

Fonte: Banco de dados da pesquisa.

O gráfico ilustra o resultado dos pais que, enfaticamente, $(96,9 \%)$ disseram não concordo, à afirmativa: "Eu usufruo do conhecimento produzido pela escola", e a maioria dos pais não concorda com nenhuma afirmativas de usufruto.

\section{Considerações Finais}

O objetivo geral da pesquisa teve seu alcance através do estudo de caso que investigou a prática da gestão participativa em 12 (doze) escolas da rede municipal.

As observações permitiram conhecer na dinâmica do cotidiano da escola as percepções de seus usuários, sobre o modelo de gestão. A partir do quadro de referência construído e dos dados da realidade, foi possível responder a questão inicial: como a prática da gestão participativa é percebida pelos usuários das escolas municipais da Secretaria Executiva Regional II?Aqui pretende-se destacar que os sujeitos que tecem as relações trazem nas diferentes percepções toda a complexidade de suas formações, valores, herança cultural e personalidade e a participação nas escolas pesquisadas ocorre em níveis e graus diferenciados, através das ações entre os atores que constroem a rede de relações, onde se entremeiam resquícios da diretividade e atitudes colaborativas, não podendo as manifestações serem classificadas em um único grau ou nível, mas que a gestão participativa é um processo em aprendizagem.

As relações entre os atores que fazem a vida da escola criam o lugar da troca, do intercâmbio e da ajuda mútua no trabalho. Esta relação foi verificada na maioria das escolas, nos diferentes ambientes e situações. Foi possível observar uma clareza sobre a gestão participativa, enquanto gestão humanizada. Por outro lado, faltam os mecanismos e o investimento necessário para melhoria da qualidade da participação no que se refere ao conhecimento dos elementos que permitem a compreensão fundamentada e crítica da realidade. A gestão escolar apresentou caráter participativo, ao reconhecer a importância do saber dos trabalhadores. Contudo, as entrevistas apontaram que estes servidores são habitualmente convocados para a discussão de situações problemáticas e críticas, e menos convocados nas prevenções, ou seja, na formulação de estratégias de gerenciamento participativo. Isto é, a gestão participativa na escola ainda é apenas pontual, ou seja, verificada em alguns aspectos, não chegando a caracterizar as estratégias gerenciais do setor pesquisado, de acordo com as percepções dos usuários consultados.

Apesar da clareza do discurso e posicionamento dos gestores, foi possível verificar as nuances que fazem diferença em relação a idéia e a prática do modelo de gestão participativa. A comunicação topdown, pôde ser encontrada em procedimentos gerenciais, em um número restrito de escolas, onde a comunicação deveria ser orientada para o estabelecimento da comunicação em todas as direções.

Diante do quadro de percepções construído na pesquisa e considerando os postulados da literatura, que reconhece na participação um dos mais importantes temas da prática e da teoria organizacionais, e abordagem gerencial pautada na motivação, recomenda-se que novos estudos e pesquisas acadêmicas possam ser desenvolvidos de modo a ampliar, aprofundar e explorar a temática. Faz-se mister retomar a estreita relação 
existente entre a administração/gestão participativa e a educação. A administração em educação tem como um de seus importantes objetivos, a constante melhoria dos sistemas, das redes de ensino e da escola, que identificam a relevância da gestão como um meio para atingir objetivos, avaliar processos e resultados. Sob a inspiração dos teóricos pesquisados, pode-se afirmar que a consolidação de uma gestão escolar de cunho democrático-participativo requer competência cognitiva, técnica e afetiva, respaldada na internalização de valores, hábitos, atitudes e conhecimentos.

Neste sentido, recomenda-se a realização de qualificação do grupo gestor, como condição indispensável para que a participação possa efetivamente ser implementada como modelo de gestão e se consolide na prática gestora das escolas.

\section{Referências}

BORDENAVE, J. E. D. O que é participação São Paulo, Editora Brasiliense, 1983.

CARNEIRO, M. A. LDB fácil: leitura críticocompreensiva: artigo a artigo. 15. ed. Petrópolis: Vozes, 2008.

CEARÁ, Assembléia Legislativa do Estado do Ceará. Constituição do Estado do Ceará. Disponível em: www.ceara.gov.br. Acesso em: 07 out. 2009.

DEMO, P. Participação è conquista. 5. ed. São Paulo: Cortez, 2001.

LERNER, W. Organização participativa: como a empresa brasileira pode enfrentar esse desafio. São Paulo: Livraria Nobel, 1991.

LÜCK, H. A escola participativa: o trabalho do gestor escolar. 6. ed. Rio de Janeiro: DP\&A, 2004.

MAXIMIANO, A. C. A. Teoria geral da administração: da revolução urbana à revolução digital. 3. ed. São Paulo: Atlas, 2002.

MENDONÇA, L. C. de. Participação na organização: uma introdução aos seus fundamentos, conceitos e forma. São Paulo: Editora Atlas,1987. 